\title{
A clinical case of navel and joint ill in a calf - medical management
}

\begin{abstract}
An intensively managed five days old female Friesian cross breed calf weighing approximately $30 \mathrm{~kg}$ was presented to the University Veterinary Hospital, Universiti Putra Malaysia (UPM). The complaint was that the calf had swollen navel and joints and had not been able to stand up properly and frequently fell down. But the calf was alert and the appetite was normal at the time of presentation. On physical examination, body condition score was 2.5 out of 5 and and temperature was $39.3{ }^{\circ} \mathrm{C}$ (slight pyrexia), pulse and respiratory rates were within the normal range. The navel was swollen with dark necrotic tissues within the navel opening with presence of foul smelling odour. Both the carpal joints of the forelimbs and the hock joints of the hind limbs were swollen. Arthrocentesis and Jugular venipuncture were performed to collect samples for synovial fluid cytology, haematology and blood chemistry. Based on the history, physical examination and laboratory findings, the calf was diagnosed to have navel ill with associated joint ill. Treatment was performed by umbilical debridement and cleaning of necrotic tissues and debris with subsequent application of povidone of iodine. Flunixin meglumine, $1.1 \mathrm{mg} / \mathrm{kg}, 0.7 \mathrm{~mL}$, was given intramuscularly, twice daily for 3 days as analgesic, anti-inflammatory and antipyretic agent. A combination of penicillin and dihydrostreptomycin $(1.2 \mathrm{~mL})$ at a dosage of $1 \mathrm{~mL} / 25 \mathrm{~kg}$ body weight was administered intramuscularly, once daily for 5 days. Remarkable progressive improvement was observed 3 days after commencement of treatment. The umbilical care by debridement of necrotic tissues and debris and topical antisepsis, coupled with systemic antibiotic therapy using combination of penicillin and dihydrostreptomycin was effective in the treatment of navel ill and/or joint ill.
\end{abstract}

Keyword: Navel Ill; Joint Ill; Friesian Calf; Debridement 